\title{
Diferenças demográficas na Satisfação em Cursos de $e$ - learning: Uma análise com Gestores Públicos
}

\author{
Fernando Antonio de Melo PEREIRA
}

Universidade de São Paulo (USP), São Paulo, SP, Brasil

Anatália Saraiva Martins RAMOS

Universidade de São Paulo (USP), São Paulo, SP, Brasil

Maria Aparecida GOUVÊA

Universidade de São Paulo (USP), São Paulo, SP, Brasil

\begin{tabular}{c}
\hline Received 12 nov. 17; Accepted 5 dez. 17 \\
Evaluation System: Guest Article \\
Editor: Jose Lindenberg Julião Xavier Filho, Dr. \\
ISSN: 2594-8040
\end{tabular}

To cite this paper: Pereira, F. A. M.; Ramos, A. S. M. \& Gouvêa, M. A. (2017). Diferenças demográficas na Satisfação em Cursos de e-learning: Uma análise com gestores públicos. Journal of Perspectives in Management-JPM, 1(1), p. 2-20.

\section{Resumo}

O e-learning é uma tecnologia de informação e comunicação que vem ganhando espaço em ambientes organizacionais privados e públicos. Também configura uma modalidade de ensino em constante desenvolvimento. O estudo pretendeu avaliar satisfação e intenção de continuidade de uso em serviços de e-learning, categorizados por variáveis demográficas. A pesquisa apresenta uma abordagem quantitativa (survey online), obtendo uma amostra correspondente a 343 observações. A análise dos dados envolveu o uso de análise multivariada de variância (MANOVA). Os resultados apontam diferenças significativas entre as variáveis de satisfação e intenção de continuidade de uso por faixa etária e a combinação de gênero e faixa etária. O estudo tem implicações práticas na intensificação do uso de serviços de e-learning para treinamentos online em organizações públicas, além de difundir uma ferramenta de avaliação de resultados capaz de avaliar comportamentos dos funcionários em relação ao uso da tecnologia por grupos demográficos.

Palavras-Chave: E-learning; Satisfação; Gestão Pública; MANOVA. 


\section{Introdução}

$\mathrm{O}$ uso de tecnologias da informação e comunicação na educação continua a se desenvolver em ambientes organizacionais privados e públicos. $\mathrm{O}$ e-learning é uma dessas tecnologias, podendo ser definido como uma modalidade de educação à distância, baseado em aprendizagem via web com uso de plataformas virtuais de ensino (Nicholson, 2007; Kaplan e Leiserson, 2012). Existem inúmeras ferramentas de avaliação de resultados em serviços de e-learning, incluindo abordagens subjetivas de acompanhamento dos sentimentos e percepções de alunos durante um curso a distância (Lai, 2008; Duque \& Weeks, 2010).

Muitos estudos têm sido conduzidos para examinar a interação dos estudantes com serviços de e-learning e serviços de base tecnológica em geral (Chiu et al., 2005; Hung \& Cho, 2008; Chou et al., 2010; Saha, Nath \& Sangari, 2010). Em contraste, poucos estudos têm sido realizados para examinar temas dessa natureza em países em desenvolvimento (Lai, 2008; Middlehurst \& Woodfield, 2006). No Brasil, os estudos sobre e-learning tem foco nas implementações de cursos à distância nas universidades e, sob a forma de treinamentos no setor privado. No setor público, ainda há carência de estudos com foco na capacitação por meio do $e$ learning (Pereira, Ramos, Gouvêa \& Costa, 2015). Além disso, há carência de estudos que investiguem possíveis efeitos de confundimento ou influência de variáveis demográficas que influenciem os níveis de satisfação do usuário.

Existem inúmeros ambientes organizacionais em que o e-learning é implementado e esses ambientes normalmente se complementam, como afirmam Duque e Weeks (2010). O setor público está enxergando a capacitação online para seus funcionários como medida eficaz e barata para atingir melhores resultados organizacionais (Huertas, 2007; Barbosa, 2007; Langford \& Seaborne, 2008). Capacitação pode ser entendida como "um processo permanente e deliberado de competências institucionais por meio de competências individuais" (Brasília, 2006, p.1).

Para verificar a taxa de sucesso e tendência de crescimento dos serviços de e-learning são avaliados aspectos comportamentais que avaliam a expectativa, a aceitação, o uso e a própria performance na forma de aprendizagem com uso de plataformas virtuais (Erdogmus \& Esen, 2011; Liao et al., 2011; Kim et al., 2012; Terzis, Moridis \& Economides 2013). A satisfação é recorrente em estudos de e-learning por avaliar se a tecnologia utilizada nos cursos está sendo aceita e bem aproveitada (Lai, 2008). Além disso, a satisfação e a intenção de continuar realizando cursos são variáveis resposta do sucesso dos cursos.

Com base nesse contexto, a proposta deste artigo é introduzir um modelo de satisfação e intenção de continuidade de uso de serviços de e-learning, testando padrões de comportamento categorizados por variáveis demográficas, como gênero e faixa etária, a fim de responder a seguinte questão de pesquisa: Existem diferenças de médias significativas na avaliação de variáveis dependentes (satisfação e intenção de continuidade de uso de serviços de e-learning) ao longo de grupos formados por características específicas de variáveis do perfil demográfico?

A pesquisa é aplicada a funcionários de organizações públicas localizadas no estado do Rio Grande do Norte, no nordeste brasileiro.

A hipótese central deste trabalho pode ser assim enunciada: Indicadores de satisfação e de intenção de continuidade de uso de serviços de e-learning têm médias diferentes em segmentos específicos de seus usuários.

O texto deste artigo está dividido em seis tópicos, incluindo este tópico introdutório. O segundo tópico aborda o conceito de e-learning e tendências em estudos de e-learning. O terceiro tópico discorre sobre os procedimentos metodológicos. O quarto tópico apresenta os resultados encontrados a partir da pesquisa empírica. Nos tópicos finais, consta a discussão dos resultados e demais considerações finais.

\section{Referencial Teórico}

Esta seção apresenta a conceituação do $e$ learning e um breve histórico de sua evolução, seguindo com as principais tendências do e-learning nas organizações, por meio de estudos recentes que tem como enfoque a avaliação do serviço, tal avaliação tendo como variáveis resposta a satisfação e a intenção de continuidade de uso. A gestão pública é discutida no tópico 2.3, avaliando o contexto histórico da implementação do e-learning no serviço público através da literatura atual sobre a reforma do Estado e recentes avaliações de iniciativas de implementar o e-larning em organizações públicas nacionais. 


\subsection{E-learning: Aspectos Gerais}

A evolução das Tecnologias de Informação e Comunicação (TICs) aliada à popularização de tecnologias como a internet possibilitou para o ensino o desenvolvimento de novos ambientes de aprendizagem. Dentre esses ambientes, pode-se destacar o e-learning que é definido pela American Society for Training and Development's como "um amplo conjunto de aplicações e processos, tais como aprendizagem via web, baseada em computador, salas de aula virtuais e colaboração digital" (Kaplan \& Leiserson, 2012, p. 85).

A partir deste conceito, nota-se que o e-learning diz respeito à utilização de tecnologias da internet com o objetivo de ofertar grande quantidade de soluções que incrementem o conhecimento e o desempenho (Palkovits, Lorente \& Paragiannis, 2002). O uso da internet como forma de comunicação faz com que essa ferramenta de aprendizagem seja assimilada como uma modalidade de Ensino a Distância (EaD), onde o aprendizado é planejado para ocorrer em local diferente do ensino, por meio de técnicas especiais de criação do curso e de instrução, comunicação através de várias tecnologias e disposições organizacionais e administrativas especiais (Moore \& Kearsley, 2007).

No EaD, identifica-se a ocorrência de quatro gerações, três delas destacadas por Niper (1989), a saber: a) o ensino por correspondência; b) o ensino multimídia e; c) novas tecnologias de comunicação científica. $\mathrm{O}$ e-learning encabeçaria uma nova geração, pois sua proposta rompe com o modelo tradicional de ensino em busca de uma maior inclusão. A partir dessa mudança de foco na tecnologia da educação, Nicholson (2007) elucida as fases históricas do e-learning, apresentadas no quadro 1.

Quadro 1: Fases históricas do E-learning

\begin{tabular}{|c|c|c|}
\hline Era & Foco & Características \\
\hline $1975-1985$ & $\begin{array}{c}\text { Programação; Computer } \\
\text { Assisted Learning (CAL). }\end{array}$ & $\begin{array}{c}\text { Abordagem behaviorista à aprendizagem e instruções; Uso de } \\
\text { programação para construir e resolver problemas. }\end{array}$ \\
\hline $1983-1990$ & $\begin{array}{c}\text { Treinamento baseado em } \\
\text { computador; Multimídia. }\end{array}$ & $\begin{array}{c}\text { Uso de modelos antigos (CAL) com material didático multimídia. } \\
\text { Projetos de softwares educacionais mais intuitivos e focados no } \\
\text { usuário. }\end{array}$ \\
\hline $1990-1990$ & Treinamento baseado na web & $\begin{array}{c}\text { Internet baseada em entrega de conteúdo; Interações limitadas ao } \\
\text { usuário final. }\end{array}$ \\
\hline $1995-2005$ & E-learning & $\begin{array}{c}\text { Internet baseada na flexibilidade, aumento da interatividade, } \\
\text { material didático online e interações usuário-usuário. }\end{array}$ \\
\hline $2005-$ Atual & $\begin{array}{c}\text { Mobile learning; MOOCs } \\
\text { (Massive Open Online Courses) }\end{array}$ & $\begin{array}{c}\text { Aprendizagem a partir de dispositivos móveis; Cursos abertos à } \\
\text { distância, com uso de Web 2.0 e redes sociais. }\end{array}$ \\
\hline
\end{tabular}

Fonte: Adaptado de Nicholson (2007, p. 7).

O Quadro 1 procura mostrar a interação entre as mudanças de paradigmas ao longo do tempo e também que as noções contemporâneas de $e$ learning estão focadas na popularização do computador, na democratização da internet e na oferta de cursos de alta qualidade para um grande número de pessoas (Guerra et al., 2012; Carr, 2012). Nesse quadro ainda é possível verificar a influência dos sistemas de aprendizagem do passado, se forem considerados os esforços em desenvolver conhecimentos e competências em busca da criação de novos conhecimentos.

$\mathrm{O}$ uso do e-learning como ferramenta de aprendizagem constitui-se como um processo de aprendizagem centrado no aluno onde ele interage com os recursos disponíveis, de maneira flexível, conforme sua capacidade de aprendizagem. Logo, nota-se que existe um processo de auto formação que rompe as barreiras existentes no processo tradicional de ensino, que é focado no relacionamento professor/aluno, "sendo o professor/formador o catalizador do desenvolvimento deste processo" (Barbosa, 2007, p. 2).

Nos serviços de e-learning, a interação e acúmulo de conhecimento dos usuários são realizados por meio dos ambientes virtuais de aprendizagem (AVA) ou (Virtual Learning Environment - VLE). "Um AVA é um sistema que reúne uma série de recursos e ferramentas, permitindo e potencializando sua utilização em atividades de aprendizagem através da internet em cursos à distância" (Vavassori, Raabe \& Alice, 2003, p. 312). Esses sistemas/ambientes são softwares desenvolvidos em linguagem de programação visual para a web (Silva, 2009) de tal 
forma que seja possível a criação e administração de cursos na modalidade a distância. O software é considerado "um facilitador, um meio de interação, de troca de informações, de armazenagem, de auxílio, enfim, uma ferramenta que age como catalisador do processo do conhecimento" (Pereira, 2013, p. 24).

Além do uso de softwares, há outras modalidades de mídia utilizadas para prover os serviços de $e$ learning, de forma a revelar uma sub-modalidade de ensino chamada blended learning ou e-learning híbrido. O blended learning é um conceito de educação caracterizado pelo uso de soluções mistas, "utilizando uma variedade de métodos de aprendizagem que ajudam a acelerar o aprendizado, garantem a colaboração entre os participantes e permitem gerar e trocar conhecimentos" (ENAP, 2008, p. 85).

Essa modalidade de aprendizagem pode utilizar diversos meios de ensino, tais como teleconferência, CD-ROM, internet, jogos e trabalhos em grupo, cuja escolha irá depender tanto do público alvo com que se quer trabalhar bem como das competências e objetivos a serem alcançados (Pereira, 2013), seja por intermédio da interação síncrona ou assíncrona (Almeida, 2003; Araújo, Rios \& Machado, 2005). Quanto à definição dessas interações, a primeira (síncrona) como a informação sendo transmitida em tempo real (chats e messengers) e a segunda (assíncrona), em modo diferido, como o correio eletrônico, ou uso de videos e apostilas digitais.

Para oferecer o serviço de e-learning, é necessário haver condições básicas que, de acordo com Pinheiro (2004), são: "conexão em rede", "disponibilização de conteúdos para o aluno via computador" e "foco em uma visão ampla de aprendizado", que possibilita o advento de soluções que vão além dos paradigmas tradicionais de treinamento.

Em relação aos fatores críticos para o sucesso desse sistema de aprendizagem, Masoumi (2010) lista sete, tais como: apoio institucional, desenvolvimento do curso, ensino e aprendizagem, estrutura do curso, apoio ao usuário, avaliação e acompanhamento. Já Selim (2005), aponta: características do instrutor, características dos usuários, conteúdo do curso, AVA, facilidade de acesso, apoio institucional, colaboração interativa e infraestrutura. Logo, pode-se perceber que o que eles apresentam em comum é a defesa da tentativa em fornecer uma base pedagógica como pré-requisito (Masoumi, 2010; Pereira, 2013).

\subsection{Tendências nos estudos em e-learning}

A satisfação no contexto do marketing e da tecnologia da informação pode ser conceituada como "um sentimento individual de prazer ou desapontamento resultante da comparação de performances percebidas em relação às expectativas" (Chiu et al., 2005, p. 406). A performance ou desempenho é uma crença em relação aos atributos de um produto ou serviço (Spreng, Mackenzie \& Olshavsky, 1996). De valor da informação e qualidade de um sistema, vários estudos remodelaram o desempenho percebido para defini-lo como um fator contribuinte para a satisfação (Kim et al., 2012; Terzis, Moridis \& Economides, 2013). Oliver (1980) teoriza que a satisfação está associada positivamente com uma intenção futura e produz uma contribuição para um maior conhecimento.

A satisfação também pode estar relacionada à motivação ou ao desejo de continuar utilizando um determinado produto ou serviço. Liao et al. (2011, p. 242) afirmam que "a satisfação com um produto ou serviço é a principal motivação para sua continuidade de uso". Existem inúmeros estudos na literatura que estabelecem o vínculo entre a satisfação e variáveis dependentes de desfecho, entre elas a intenção de continuidade de uso (Cheung \& Lee, 2011; Liao et al., 2011; Chiu et al., 2005; Kim et al., 2012; Terzis, Moridis \& Economides, 2013).

Estudos de satisfação em e-learning vem ganhando importância quando aplicados fora do ambiente de ensino e meio corporativo, pois o $e$ learning tem sido utilizado em cursos de capacitações e treinamentos nos órgãos governamentais, demonstrando ser uma importante ferramenta de governo eletrônico (Langford \& Seaborne, 2008; Pinho \& Macedo, 2008; Hung \& Cho, 2008; Saha, Nath \& Sangari, 2010; Chou et al., 2010; Fu et al., 2007).

Diversos estudos avaliam se aspectos ligados à satisfação e intenção de continuidade de uso em serviços de e-learning sofrem influência de fatores ligados ao perfil demográfico, com maior ênfase aos estudos que abordam gênero e faixa etária (Duque \& Weeks, 2010; Gomez et al., 2012; Lai, 2008; Summak, Baglibel \& Samancioglu, 2010).

A pesquisa de Gomez e colaboradores (2012) constatou que as mulheres estão mais satisfeitas que os homens com os serviços de e-learning oferecidos. No entanto, as mulheres dão mais importância ao contato com o professor, que não seja apenas por meio do AVA. Não foram encontradas diferenças 
significativas em relação aos motivos de procura por cursos. Ramos (2008) avaliou aspectos de gênero no uso de softwares livres, partindo da premissa de que homens e mulheres possuem comportamentos diferentes diante da tecnologia.

Já Duque e Weeks (2010) utilizaram a análise de variância para comparar a opinião de usuários de $e$ learning na percepção de aspectos comportamentais e da qualidade dos cursos realizados. Os resultados mostraram diferenças significativas de desempenho e importância dada pelos alunos aos aspectos analisados. Galinkin (2010) avaliou o uso de tecnologias móveis no auxílio à aprendizagem, caracterizando o chamado mobile learning, especificamente para o público dos idosos. Os resultados mostraram que a terceira idade era adepta a esse novo modelo de aprendizagem e oferecia baixa resistência à utilização de tecnologias em geral como meio para aprender.

\section{$2.3 \mathrm{O}$ e-learning na gestão pública brasileira}

No âmbito da gestão pública, os conceitos de satisfação e continuidade de uso, originários da literatura da área de Marketing são aplicados da mesma maneira, sendo o usuário ou aluno visto como cliente, que deposita expectativas no serviço e espera que estas expectativas sejam atendidas e superadas. Essa visão fica clara a partir de iniciativas do Governo Federal no final dos anos 1990 e início do Século XXI.

A chamada Nova Gestão Pública (NGP), sendo um movimento reformista do Estado, adotado por diversos países, teve início no Brasil a partir do Plano Diretor da Reforma do Aparelho do Estado, formulado pelo Ministério da Administração Federal e Reforma do Estado (MARE), que seguiu os preceitos básicos da NGP (Sano \& Abrúcio, 2008).

A NGP abriu caminho para iniciativas como o programa GESPÚBLICA, instituída pelo Governo Federal, por meio do Decreto n. 5.378 de 23 de Fevereiro de 2005, que versa sobre o programa com a finalidade de diminuir a intensa burocratização e difundir um modelo de gestão pública de excelência. A meta principal do programa é ser de excelência, sem deixar de ser público. O programa indica fundamentos ou critérios que devem ser seguidos, sendo um deles o critério "Informação e Conhecimento", que envolve a orientação por processos e informações, referentes à compreensão e segmentação das atividades da organização que agreguem valor para as partes interessadas (GESPÚBLICA, 2010). Dentre os princípios seguidos por este critério, está o aprendizado organizacional, tal como define Senge (1998), como uma busca contínua e alcance de novos patamares de conhecimento, individuais e coletivos, por meio da percepção, reflexão, avaliação e compartilhamento de informações e experiências.

Outra iniciativa que parte do preceito básico de flexibilização da gestão burocrática, é o Decreto n. 5707 de 23 de Fevereiro de 2006, que institui uma política de diretrizes para desenvolvimento de pessoal da administração pública (BRASÍLIA, 2006). O decreto traz em seu escopo diretrizes para implementação de treinamentos e capacitações à distância, com o objetivo de reduzir custos, mas também seguindo os moldes da NGP no Brasil, que tem como fatores decisivos a eficiência e eficácia da máquina pública, associada ao fator inovação, incorporado às aplicações de e-learning.

Dessa forma, o e-learning encontra espaço na gestão pública, pois é embasado na área pelos preceitos que regem a NGP e atende as necessidades atuais da gestão pública nacional, por meio da eficiência, da redução de custos, da inovação e da aprendizagem organizacional. A necessidade de treinamentos mais especializados e em maior número, além da facilidade em registrar e difundir conhecimentos, garantiu uma posição de destaque dos serviços de e-learning na área pública. O desafio do Estado nesse momento é garantir que as iniciativas alcancem os objetivos e obtenham sucesso. Para que isso aconteça, uma avaliação criteriosa da efetividade dos cursos de e-learning é determinante do sucesso das iniciativas adotadas.

A fundamentação teórica apresentada nesta seção serviu de apoio para o desenvolvimento de uma pesquisa sobre e-learning cujos principais aspectos metodológicos são descritos no próximo item.

\section{Procedimentos Metodológicos}

O presente estudo caracteriza-se como uma pesquisa exploratória. A pesquisa exploratória proporciona maior familiaridade com o problema, com vistas a torná-lo mais explícito ou a construir hipóteses (Vergara, 2008; Silva \& Menezes, 2001). Atuam como unidades de análise duas organizações públicas localizadas no estado do $\mathrm{RN}$, no nordeste brasileiro, são elas: a Universidade Federal do Rio Grande do Norte (UFRN) e o Ministério Público do Rio Grande do Norte (MPRN).

A população da pesquisa consiste em todos os funcionários que já atuaram como usuários de serviços de e-learning nas organizações estudadas. 
A população foi dividida em dois subgrupos. Para garantir a homogeneidade entre os subgrupos, foi adotada a amostragem estratificada ótima, que considera em cada estrato amostral, um número de observações proporcional ao número de elementos do estrato na população. Dessa forma, uma quantidade equivalente de observações de cada organização foi coletada (Magalhães \& Lima, 2002). Os subgrupos foram analisados em conjunto após avaliação de cargas cruzadas, não sendo encontradas variações relevantes nas respostas dadas pelos estratos formados pelos funcionários da UFRN e do MPRN. Esses resultados indicam que as autoavaliações realizadas pelos respondentes são similares quando comparadas as duas unidades de análise e, portanto, podem ser analisadas em conjunto.

Para a composição da amostra, também foi levada em consideração a exigência de tamanho de amostra para atingir poder estatístico de 0,80 na Análise Multivariada de Variância (Multivariate Analysis of Variance - MANOVA).

Dois modelos serão testados neste trabalho:

1 - Indicadores de satisfação versus perfil do usuário do serviço

2 - Indicadores de intenção de continuidade de uso de serviços de e-learning versus perfil do usuário do serviço

As variáveis dependentes nos dois modelos são, respectivamente, indicadores de satisfação (três itens) e indicadores de intenção de continuidade de uso de serviços de e-learning (três itens).

As variáveis independentes retratam características demográficas dos usuários em termos de gênero e faixa etária.

Com base nas variáveis independentes, o gênero (dois estratos) e a faixa etária (cinco estratos) produzem dez grupos em cada modelo. Com o uso de dois modelos com três variáveis dependentes e dez grupos formados, o número de observações exigido para se garantir poder estatístico de 0,80 é de 125. A amostra da pesquisa, formada por 343 casos, possui um número maior do que o estipulado.

O processo de coleta se deu por um questionário do tipo survey online, enviado por e-mail para o público-alvo, contendo um texto de apresentação e hiperlink dando acesso ao questionário. $\mathrm{O}$ preenchimento foi de caráter voluntário, realizado no mês de Fevereiro de 2013. As respostas foram hospedadas na ferramenta Form do Google Drive, sendo importadas para o software Statistical Package for the Social Sciences (SPSS v. 21), utilizado para a análise de estatística descritiva e uso da MANOVA.

A análise de variância (ANOVA) é utilizada para determinar se as amostras de dois ou mais grupos surgem de populações com médias diferentes. A ANOVA examina uma variável dependente, "ao passo que a análise multivariada de variância (MANOVA) compara diferenças de grupos quanto a duas ou mais variáveis dependentes (Hair et al., 2009 , p. 304). A pesquisa foi alicerçada pela teoria vigente, onde se propõe a investigar a diferença de médias das variáveis dependentes de satisfação e de intenção de continuidade de uso em função dos grupos formados pelas combinações das categorias de gênero e faixa etária.

Para isso foram formados dois modelos de análise, ambos integrados pelas variáveis do perfil gênero e faixa etária e três variáveis dependentes, o primeiro contendo as variáveis de satisfação e o segundo contendo as variáveis de intenção de continuidade de uso. De acordo com o Quadro 2, a técnica mais apropriada de operacionalização dos modelos propostos é a MANOVA por ser a técnica de análise de variância que suporta modelos com dois ou mais grupos e com duas ou mais variáveis dependentes.

Quadro2: Relação entre procedimentos uni e multivariados

\begin{tabular}{|ccc|}
\hline & \multicolumn{2}{c|}{ Número de variáveis dependentes } \\
\hline Número de grupos em variável independente & Uma (univariada) & Duas ou mais (multivariada) \\
\hline Dois grupos (caso especializado) & Teste T & $\mathrm{T}^{2}$ de Hotelling \\
\hline Dois ou mais grupos (caso generalizado) & Análise de variância (ANOVA) & $\begin{array}{c}\text { Análise multivariada de variância } \\
\text { (MANOVA) }\end{array}$ \\
\hline
\end{tabular}

Fonte: Hair e colaboradores (2009:306). 
Um teste piloto do questionário foi realizado com sete funcionários de ambas as organizações, escolhidas por conveniência dos pesquisadores "com o objetivo de evitar vieses, corrigir falhas e ambiguidade e acrescentar ou modificar questões caso fosse necessário" (Carvalho, 2009, p. 146). Não foram adicionados itens, no entanto, o questionário sofreu alterações na redação das perguntas para facilitar a compreensão dos respondentes sobre os itens avaliados. Dessa forma, possíveis vieses referentes ao contexto do item foram minimizados.

\section{Resultados}

Inicialmente serão apresentadas as principais características da amostra coletada nesta pesquisa. $\mathrm{Na}$ sequência, os maiores destaques da aplicação da MANOVA.

\subsection{Perfil da amostra}

Ao analisar inicialmente o perfil dos colaboradores do MPRN e da UFRN, objetiva-se identificar as suas características demográficas predominantes para posteriormente verificar se os mesmos avaliam de forma distinta a satisfação e a intenção de continuidade de uso dos serviços de $e$ learning. Para a formação do perfil demográfico, foram considerados gênero, faixa etária, estado civil, escolaridade e renda familiar.

Com relação ao gênero, há um equilíbrio entre respondentes, com uma leve predominância de respondentes do sexo feminino $(51,9 \%)$. No tocante à faixa etária, apresentada no Gráfico 1, a maioria dos respondentes tem entre 18 e 25 anos $(36,4 \%)$, acompanhados daqueles que possuem idade entre 26 e 35 anos $(30,9 \%)$. Esses resultados demonstram existir em ambas as organizações estudadas uma distribuição equitativa de homens e mulheres, predominando a existência de um corpo funcional jovem com idades até 35 anos.

A variável que mensura o estado civil dos participantes da pesquisa revela a predominância de pessoas solteiras compondo pouco mais de $50 \%$ da amostra. Esse resultado está conectado com o perfil da faixa etária, indicando a prevalência de colaboradores jovens. Em relação à escolaridade, houve um equilíbrio entre respondentes com curso superior incompleto e aqueles que possuem pósgraduação completa, indicando uma tendência possuir no futuro uma parcela maior com curso superior completo. A última variável de perfil mensurada foi a renda familiar. Grande parte dos respondentes possui renda familiar abaixo de seis salários mínimos, concentrando-se nas duas faixas inferiores de renda, sendo de 1 a $3(36,5 \%)$ e de 4 a $6(34,4 \%)$.

Gráfico 1: Faixa etária

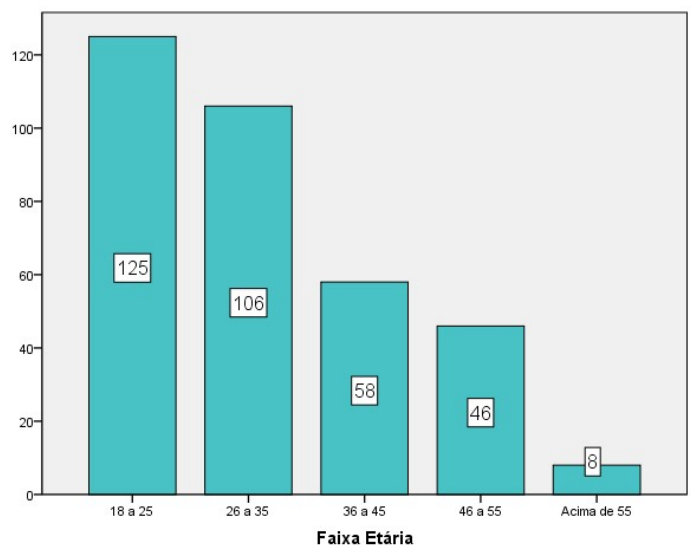

Esse resultado analisado em conjunto com as variáveis apresentadas anteriormente demonstra que a força de trabalho exigida em ambas as organizações é predominantemente formada de cargos operacionais, porém apresentando uma parcela significativa de cargos em níveis estratégicos. Conclui-se que há uma predominância de respondentes do sexo feminino, com idade entre 18 e 25 anos, solteiras, com curso superior incompleto e com renda familiar de 1 a 3 salários mínimos.

\subsection{Variáveis dependentes}

Os itens que formam a satisfação e a intenção de continuidade de uso são encontrados em pesquisas que abordam o e-learning, tais como as de Chiu e colaboradores (2005), Liao e colaboradores (2011), Kim e colaboradores (2012), Terzis, Moridis e Economides (2013), entre outros. As variáveis utilizadas na pesquisa são apresentadas no Quadro 3.

Para avaliar as variáveis dependentes fez-se uso de histogramas ou gráfico de barras verticais com curva normal que permite analisar a distribuição de frequência de forma que contribua para a melhor compreensão dos dados. A curva normal foi incluída nos histogramas, pois descreve a distribuição esperada da amostra, permitindo visualizar ocorrências assimétricas caso existam nas formas de 
distribuição das variáveis. "Os gráficos e tabelas ajudam a compreender mais facilmente os dados. Eles também comunicam de modo mais eficiente assuntos complexos e tornam seu relatório de pesquisa mais atraente" (Hair et al., 2010:261). Foram encontradas leves assimetrias à direita, evidenciando o alto grau de concordância dos respondentes.
A próxima etapa na avaliação das variáveis dependentes é buscar responder a questão: Existem diferenças de médias significativas na avaliação de variáveis dependentes em grupos de usuários com características específicas do perfil demográfico?

Quadro 3: Variáveis da pesquisa

\begin{tabular}{|c|c|c|}
\hline \multirow{3}{*}{$\begin{array}{l}\text { Satisfação } \\
\quad(\text { SAT })\end{array}$} & $\begin{array}{l}\text { SAT1 - Satisfação no } \\
\text { uso }\end{array}$ & Estou satisfeito com meu desempenho no curso que realizei \\
\hline & $\begin{array}{l}\text { SAT2 - Experiência } \\
\text { atrativa }\end{array}$ & Sinto-me satisfeito com a experiência de realizar cursos à distância \\
\hline & SAT3 - Aprecia o uso & $\begin{array}{c}\begin{array}{c}\text { Sinto que tomei uma decisão sábia ao escolher realizar um curso a } \\
\text { distância }\end{array} \\
\end{array}$ \\
\hline \multirow{3}{*}{$\begin{array}{c}\text { Intenção de } \\
\text { Continuidade } \\
\text { de Uso } \\
\text { (COS) }\end{array}$} & COS1 - Pretensão de uso & $\begin{array}{l}\text { Pretendo continuar realizando cursos a distância com uso de ferramentas } \\
\text { como o AVA }\end{array}$ \\
\hline & COS2 - Intenção de uso & Vou continuar realizando cursos a distância \\
\hline & $\begin{array}{c}\text { COS3 - Regularidade no } \\
\text { uso }\end{array}$ & Vou realizar regularmente cursos a distância \\
\hline
\end{tabular}

Fonte: Elaborado pelos autores, 2016.

\subsection{Análise multivariada de variância entre Satisfação versus Perfil}

No estudo das variáveis dependentes ainda se faz necessário comparar as médias das variáveis dependentes em grupos de acordo com as variáveis do perfil. Em estudos que abordam o e-learning, como o de Gomez e colaboradores (2012) e de Summak, Baglibel e Samancioglu (2010) são realizadas análises multivariadas de variância utilizando o gênero e faixa etária para identificar possíveis diferenças de médias de avaliação da satisfação e intenção de continuidade de uso em serviços de e-learning nos estratos.

A utilização da MANOVA se justifica por ela acomodar mais de uma variável dependente, permitindo a condução dos modelos dessa pesquisa, com três variáveis dependentes cada. Em um primeiro estágio, foram avaliadas as premissas para utilização da MANOVA, conforme é mostrado na Tabela 1.

Para atender a premissa de igualdade das matrizes, foi conduzido o teste Box $\mathrm{M}$, apresentando significância de 0,037 . A expectativa nesse teste é a não rejeição da hipótese nula. Hair e colaboradores (2009) argumentam que esse teste é sensível a flutuações e dimensionamentos amostrais, verificado na pesquisado pelo tamanho desigual dos grupos. Portanto, com o resultado do teste se aproximando da fronteira de aceitação, considera-se que não houve grandes desvios da premissa estabelecida, o que não inviabiliza o uso da técnica. Nos demais testes, percebe-se que as premissas são atendidas. Dessa forma, a MANOVA pode ser conduzida.

O método utilizado para identificação de outliers foi a distancia de Mahalanobis, sendo considerado o método mais adequado no uso de técnicas multivariadas (Hair et al. 2009). Verificadas simultaneamente, foi calculado um centroide e as distancias de Mahalanobis de cada observação em relação a esse centroide. Ao todo, 11 observações obtiveram distâncias que excederam o valor crítico, obtido na distribuição $t$ de student. Dessa forma, a amostra, antes com 343, foi composta por 332 respondentes. 
Tabela 1: Premissas da MANOVA para o construto Satisfação

\begin{tabular}{|c|c|c|c|}
\hline Premissa & Teste & Estatística & Diagnóstico \\
\hline $\begin{array}{l}\text { Normalidade } \\
\text { multivariada das } \\
\text { variáveis dependentes }\end{array}$ & $\begin{array}{c}\text { Assimetria (sk)e } \\
\text { curtose (ku) }\end{array}$ & $S k<[3]$ e $K u<[3]$ & $\begin{array}{l}\text { A distribuição das variáveis não viola o } \\
\text { pressuposto da normalidade } \\
\text { multivariada, obtendo valores menores } \\
\text { do que } 3 \text { em módulo e próximos de } 0 .\end{array}$ \\
\hline \multirow{2}{*}{$\begin{array}{l}\text { Igualdade de matrizes } \\
\text { de variância e } \\
\text { covariância }\end{array}$} & $\begin{array}{l}\text { Teste de igualdade de } \\
\text { variâncias de erro de } \\
\text { Levene }\end{array}$ & $\begin{array}{l}\text { Sat } 1=0,010 \\
\text { Sat } 2=0,011 \\
\text { Sat } 3=0,059\end{array}$ & $\begin{array}{c}\text { As variâncias da variável Sat3 são } \\
\text { diferentes nos grupos com nível de } \\
\text { significância a 5\%. As variâncias das } \\
\text { variáveis Sat1 e Sat2 são diferentes nos } \\
\text { grupos com nivel de significância a } \\
1 \% \text {, }\end{array}$ \\
\hline & Teste Box M & $F=0,565 ;$ Sig. 0,037 & $\begin{array}{l}\text { Com Sig. < 0,05, rejeita-se a hipótese } \\
\text { nula de que há igualdade das matrizes } \\
\text { de covariância ao longo dos grupos }\end{array}$ \\
\hline $\begin{array}{l}\text { Presença de } \\
\text { correlações entre as } \\
\text { variáveis dependentes }\end{array}$ & $\begin{array}{c}\text { Teste de Esfericidade } \\
\text { de Bartlett }\end{array}$ & $\begin{array}{c}\chi^{2}=126,863 \\
\text { Sig. 0,000 }\end{array}$ & $\begin{array}{l}\text { Sig. }<0,05, \text { rejeita-se a hipótese nula de } \\
\text { que a matriz de correlação das } 3 \\
\text { variáveis dependentes é igual a matriz } \\
\text { identidade, portanto, as correlações } \\
\text { entre as variáveis é diferente de } 0\end{array}$ \\
\hline $\begin{array}{c}\text { Identificação de } \\
\text { outliers multivariados }\end{array}$ & $D^{2}$ Mahalanobis & \multicolumn{2}{|c|}{$\begin{array}{c}\text { Avalia a presença de outliers que podem influenciar nas } \\
\text { estimativas dos parâmetros. Foram excluidas } 11 \text { observações } \\
\text { do estudo, sendo estas as que obtiveram maiores indices de } \\
\text { Mahalanobis }\end{array}$} \\
\hline
\end{tabular}

Fonte: Elaborado pelos autores, 2016.

Para a MANOVA, são avaliados quatro testes comuns no uso da técnica para identificar diferenças significativas entre médias. A hipótese nula corresponde à igualdade do vetor das médias das variáveis que compõem o construto satisfação ao longo dos 10 grupos formados pelas variáveis independentes.

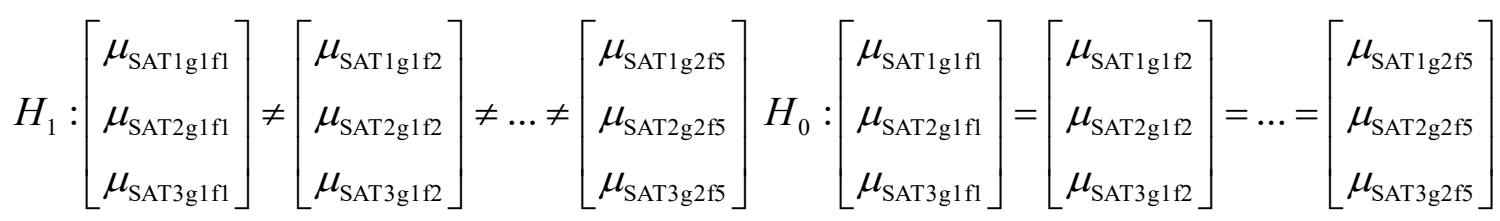

Sendo $\mathrm{g}$ =gênero com estratos 1 e 2 e $\mathrm{f}=$ =faixa etária com estratos de 1 a 5 , totalizando 10 grupos. Se confirmada a evidencia de desigualdade das matrizes em pelo menos um grupo, são realizados testes univariados com a variável do perfil, investigando seu grau de influência por variável dependente. Em seguida, os testes post-hoc identificam quais estratos da variável do perfil apresentam diferenças entre médias significativas.

O primeiro modelo contém as relações de médias das variáveis de satisfação em função do perfil (Tabela 2) sendo avaliados três testes de hipóteses, desejando-se rejeitar a hipótese nula, evidenciando médias diferentes em pelo menos um dos dez grupos formados pelas variáveis do perfil (gênero e faixa etária).

H0: A média atribuída a variável satisfação no uso é igual para os grupos formados pelas variáveis do Perfil.

H0: A média atribuída a variável experiência atrativa é igual para os grupos formados pelas variáveis do Perfil.

H0: A média atribuída a variável aprecia o uso é igual para os grupos formados pelas variáveis do Perfil. 
Tabela 2: Diferenças entre médias - Satisfação versus Perfil

\begin{tabular}{c|c|c|c|c|c|c}
\hline $\begin{array}{c}\text { Variável } \\
\text { demográfica }\end{array}$ & $\begin{array}{c}\text { Critério de } \\
\text { Pillai }\end{array}$ & $\begin{array}{c}\text { Lambda de } \\
\text { Wilks }\end{array}$ & $\begin{array}{c}\text { Lambda de } \\
\text { Hotelling }\end{array}$ & $\begin{array}{c}\text { Maior Raiz } \\
\text { de Roy }\end{array}$ & Sig. & $\begin{array}{c}\text { Poder } \\
\text { observado }\end{array}$ \\
\hline Gênero & 0,003 & 0,997 & 0,003 & 0,003 & 0,766 & 0,125 \\
\hline Faixa Etária & 0,058 & 0,942 & 0,061 & 0,052 & $\mathbf{0 , 0 2 0}$ & 0,929 \\
\hline $\begin{array}{c}\text { Gênero*Faixa } \\
\text { Etária }\end{array}$ & 0,042 & 0,958 & 0,044 & 0,036 & $\mathbf{0 , 0 1 9}$ & 0,795 \\
\hline
\end{tabular}

Diagnóstico: Encontrado diferenças de médias significativas no construto satisfação em função da faixa etária e na combinação de gênero e faixa etária.

\begin{tabular}{c|c|c|c|c|c}
\hline $\begin{array}{c}\text { Testes univariados - Faixa } \\
\text { Etária }\end{array}$ & $\begin{array}{c}\text { Soma de } \\
\text { quadrados }\end{array}$ & F & Efeito & Sig. & $\begin{array}{c}\text { Poder } \\
\text { observado }\end{array}$ \\
\hline Satisfação no uso & 73,131 & 3,436 & 0,040 & $\mathbf{0 , 0 0 9}$ & 0,854 \\
\hline Experiência atrativa & 91,876 & 3,706 & 0,043 & $\mathbf{0 , 0 0 6}$ & 0,882 \\
\hline Aprecia o uso & 107,762 & 4,071 & 0,047 & $\mathbf{0 , 0 0 3}$ & 0,913 \\
\hline $\begin{array}{c}\text { Testes univariados - Gênero } \\
\text { versus Faixa Etária }\end{array}$ & $\begin{array}{c}\text { Soma de } \\
\text { quadrados }\end{array}$ & $\mathbf{F}$ & Efeito & Sig. & $\begin{array}{c}\text { Poder } \\
\text { observado }\end{array}$ \\
\hline Satisfação no uso & 19,023 & 0,894 & 0,011 & 0,468 & 0,284 \\
\hline Experiência atrativa & 48,239 & 1,946 & 0,023 & 0,090 & 0,584 \\
\hline Aprecia o uso & 22,135 & 0,843 & 0,010 & 0,499 & 0,269 \\
\hline
\end{tabular}

De acordo com a Tabela 2, a partir dos resultados dos testes multivariados, foram encontradas diferenças significativas nas médias das variáveis de satisfação por faixa etária e na combinação de gênero e faixa etária, diagnosticados a partir da avaliação dos Critérios de Pillai, Lambda de Hotelling e Maior Raiz de Roy, os maiores índices representam uma diferença mais significativa e maior poder observado de influência é identificado. $\mathrm{O}$ índice de Lambda de Wilks é o único dentre os quatro que quanto menor mais significativo é. $\mathrm{Na}$ avaliação dos testes univariados, a faixa etária influencia as três variáveis dependentes de satisfação, obtendo a significância $(<0,05)$ e poder observado $(>0,80)$ desejado. No entanto, os testes univariados indicaram que a interação entre gênero e faixa etária apresentam diferenças de médias que não são significativas e com pouco poder observado.
A seguir, o teste post-hoc indica em quais estratos foram identificadas diferenças significativas nas médias das três variáveis para faixa etária. Os testes post-hoc para gênero não são realizados, pois possuem apenas 2 grupos.

No teste post hoc, foi utilizado o Tamhane's T2, sendo um teste baseado no teste $\mathrm{t}$ e considerado o mais robusto entre os testes indicados quando as variâncias são desiguais. Os resultados apresentaram significância abaixo de 0,05 nas relações de estratos mostradas. Uma evidência lógica é a de que os respondentes com idades entre 18 e 25 anos apresentam avaliações significativamente diferenciadas nas três variáveis de satisfação, comparados aos mais velhos. As médias dos respondentes com idades de 26 a 35 anos se mostrou diferente para aqueles com idade entre 36 e 45 anos.

Tabela 3: Teste post-hoc para Satisfação versus Faixa etária

\begin{tabular}{|c|c|c|c|}
\hline Testes post-hoc & $\begin{array}{c}\text { Tamhane's T2 } \\
\text { Diferença média }\end{array}$ & Sig. & Relação de estratos \\
\hline Satisfação no uso & $\begin{array}{l}1,2119 \\
1,0211\end{array}$ & $\begin{array}{l}0,001 \\
0,014\end{array}$ & $\begin{array}{l}18 \text { a } 25 \text { e } 36 \text { a } 45 \\
26 \text { a } 35 \text { e } 36 \text { a } 45\end{array}$ \\
\hline Experiência atrativa & $\begin{array}{l}1,2457 \\
1,1864 \\
1,1425 \\
\end{array}$ & $\begin{array}{l}0,003 \\
0,048 \\
0,015 \\
\end{array}$ & $\begin{array}{l}18 \text { a } 25 \text { e } 36 \text { a } 45 \\
18 \text { a } 25 \text { e } 46 \text { a } 55 \\
26 \text { a } 35 \text { e } 36 \text { a } 45\end{array}$ \\
\hline Aprecia o uso & $\begin{array}{l}1,3934 \\
1,3911 \\
1,0621 \\
\end{array}$ & $\begin{array}{l}0,002 \\
0,011 \\
0,050 \\
\end{array}$ & $\begin{array}{l}18 \text { a } 25 \text { e } 36 \text { a } 45 \\
18 \text { a } 25 \text { e } 46 \text { a } 55 \\
26 \text { a } 35 \text { e } 36 \text { a } 45\end{array}$ \\
\hline
\end{tabular}

A combinação de gênero e faixa etária forma 10 grupos, referentes aos dois estratos de gênero multiplicado pelos cinco estratos de faixa etária. Os gráficos de interação nas três variáveis de satisfação permitem comparar as diferenças de médias nas variáveis de satisfação ao longo desses 10 grupos. Os resultados confirmam a diferença de médias do estrato 18 a 25 em relação aos outros. No estrato acima de 55 anos, pode ser notada a maior diferença de médias por gênero nas três variáveis, sendo as 
mulheres as mais satisfeitas. No entanto, tal estrato compreende apenas oito observações da amostra, sendo considerada pouco representativa nos testes que diagnosticam diferenças nas médias, revelando o motivo para falta de significância nos testes

Gráfico 2: Interação SAT1
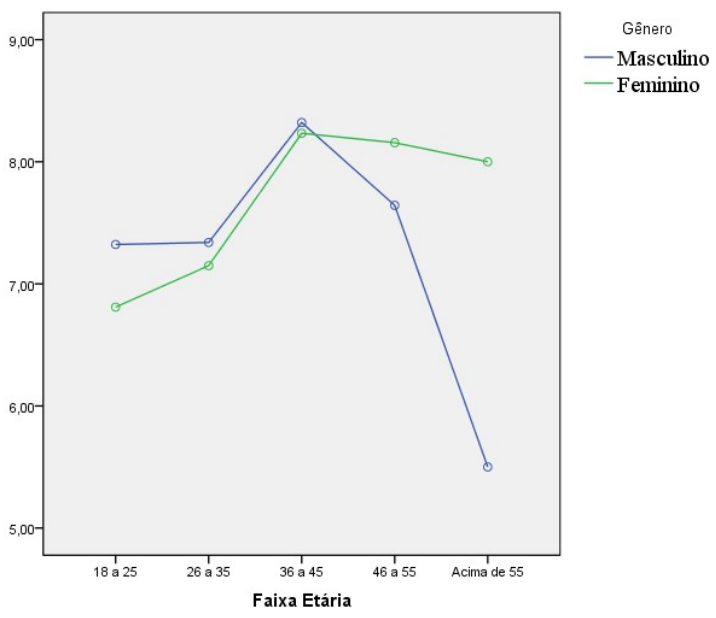

univariados para a combinação de gênero e faixa etária.
Gráfico 3: Interação SAT2

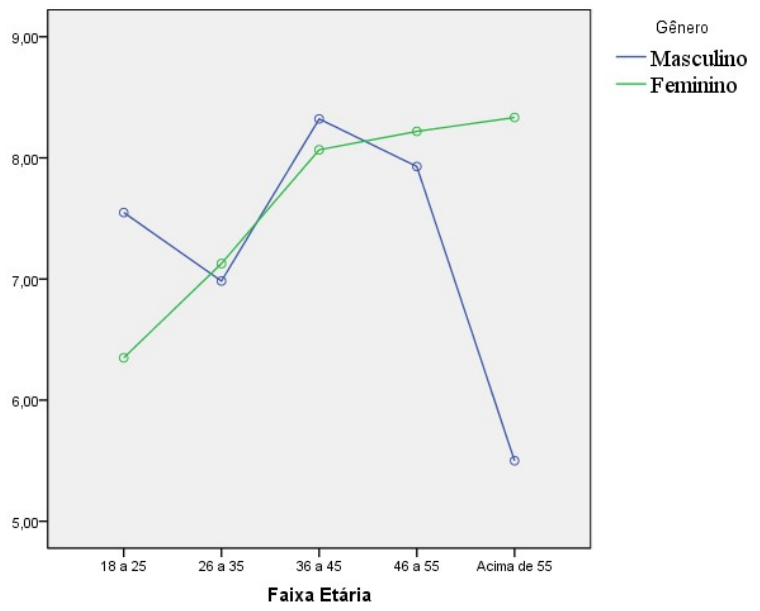

Gráfico 4: Interação SAT3

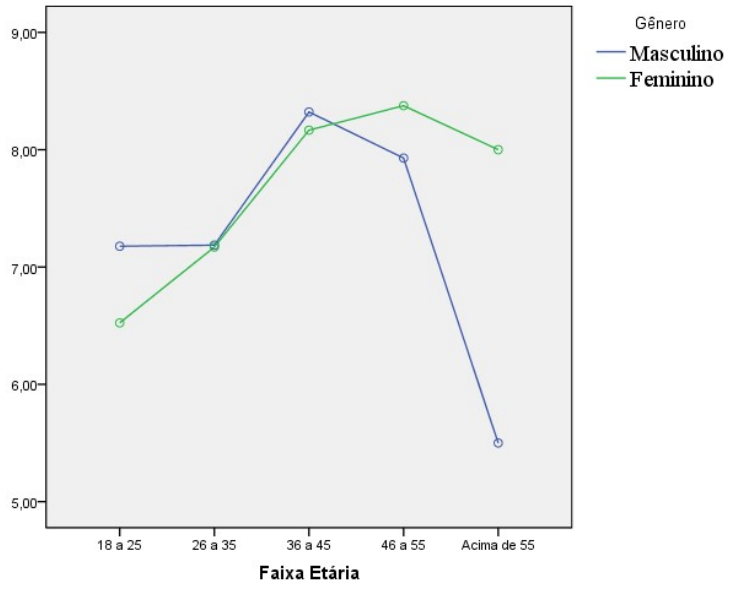

Por fim, foi utilizado o teste stepdown ou Roy Bargman. Esse teste é um procedimento post-hoc indicado quando se atinge resultados significativos na MANOVA. Consiste em ordenar as variáveis dependentes a priori, que são testadas individualmente na sequência estabelecida (Finch, 2007). O teste também indica se as correlações entre as variáveis dependentes não foram extremamente altas e se realmente cada variável contribui para a diferenciação dos grupos.
As significâncias estatísticas encontradas permitem ranquear as variáveis dependentes em relação ao nível de contribuição na diferenciação das médias encontradas por faixa etária e pela combinação de faixa etária versus gênero. A Tabela 4 apresenta os resultados do teste para o construto satisfação. 
Tabela 4: Teste Stepdown /Roy-Bargman para o construto satisfação

\begin{tabular}{c|c|c|r}
\hline \multicolumn{2}{c|}{ Stepdown para Faixa Etária } & \multicolumn{2}{c}{ Stepdown para Faixa Etária versus Gênero } \\
\hline Variáveis & Sig. dos testes & Variáveis & Sig. dos testes \\
\hline SAT1; SAT2; SAT3 & $\mathbf{0 , 0 0 7} ; 0,460 ; 0,473$ & SAT1; SAT2; SAT3 & 0,$468 ; 0,650 ; 0,747$ \\
\hline SAT2; SAT1; SAT3 & $\mathbf{0 , 0 0 4} ; 0,707 ; 0,473$ & SAT2; SAT1; SAT3 & 0,$103 ; 0,319 ; 0,747$ \\
\hline SAT3; SAT1; SAT2 & $\mathbf{0 , 0 0 2} ; 0,791 ; 0,685$ & SAT3; SAT1; SAT2 & 0,$499 ; 0,911 ; \mathbf{0 , 0 4 1}$ \\
\hline SAT1; SAT3; SAT2 & $\mathbf{0 , 0 0 7 ; 0 , 3 0 0 ; 0 , 6 8 5}$ & SAT1; SAT3; SAT2 & 0,$468 ; 0,940 ; \mathbf{0 , 0 4 1}$ \\
\hline SAT3; SAT2; SAT1 & $\mathbf{0 , 0 0 2} ; 0,694 ; 0,781$ & SAT3; SAT2; SAT1 & 0,$499 ; 0,138 ; 0,406$ \\
\hline SAT2; SAT3; SAT1 & $\mathbf{0 , 0 0 4 ; 0 , 4 1 4 ; 0 , 7 8 1}$ & SAT2; SAT3; SAT1 & 0,$103 ; 0,622 ; 0,406$ \\
\hline
\end{tabular}

Para faixa etária, os resultados mostram que as variáveis se bastam, as variáveis SAT1, SAT2 e SAT3 são significantes sozinhas e a inclusão das variáveis não ajudam a incrementar o modelo. Para a interação entre gênero e faixa etária as variáveis sozinhas não são capazes de sustentar o modelo a um nível de significância de 0,05 . As combinações SAT3; SAT1; SAT2 e SAT1; SAT3; SAT2

4.4 Análise multivariada de variância entre Intenção de Continuidade de Uso versus Perfil

As premissas para a realização da MANOVA também foram atendidas nesse caso, seguindo o mesmo procedimento adotado na análise das variáveis de satisfação. No teste de Levene, as variáveis COS1 e COS2 obtiveram significâncias de 0,012 e 0,013 respectivamente. A variável COS3 obteve significância a $5 \%$, atingindo 0,059 . No teste Box M, o índice alcançado foi de 0,035 , resultado que se aproxima do limite de aceitação, sem invalidar o uso da técnica.

Os procedimentos seguem o uso dos testes multivariados para identificar diferenças significativas entre as médias, representadas nas hipóteses a seguir. A hipótese nula corresponde à igualdade do vetor das médias das variáveis que compõem o construto intenção de continuidade de uso ao longo dos 10 grupos formados pelas variáveis independentes.

H0: A média atribuída a variável pretensão de uso é igual para os grupos formados pelas variáveis do Perfil.

H0: A média atribuída a variável intenção de uso é igual para os grupos formados pelas variáveis do Perfil.

H0: A média atribuída a variável regularidade no uso é igual para os grupos formados pelas variáveis do Perfil. obtiveram níveis de significância adequados (Sig. 0,041) após adicionar a variável SAT2, incrementando modelos formados apenas com SAT1 e SAT3. Com os resultados do teste Roy-Bargman é possível afirmar que fez sentido analisar simultaneamente as variáveis SAT1, SAT2 e SAT3, pois as variáveis apresentam um grau moderado de multicolinearidade.
As hipóteses testadas para cada variável do construto intenção de continuidade de uso têm os resultados mostrados na Tabela 5 . 
Tabela 5: Diferenças entre médias de Intenção de continuidade de uso versus Perfil

\begin{tabular}{c|c|c|c|c|c|c}
\hline $\begin{array}{c}\text { Variável } \\
\text { demográfica }\end{array}$ & $\begin{array}{c}\text { Critério de } \\
\text { Pillai }\end{array}$ & $\begin{array}{c}\text { Lambda de } \\
\text { Wilks }\end{array}$ & $\begin{array}{c}\text { Lambda de } \\
\text { Hotelling }\end{array}$ & $\begin{array}{c}\text { Maior Raiz } \\
\text { de Roy }\end{array}$ & Sig. & $\begin{array}{c}\text { Poder } \\
\text { observado }\end{array}$ \\
\hline Gênero & 0,019 & 0,981 & 0,020 & 0,020 & 0,090 & 0,553 \\
\hline Faixa Etária & 0,078 & 0,923 & 0,83 & 0,068 & $\mathbf{0 , 0 0 0}$ & 0,979 \\
\hline $\begin{array}{c}\text { Gênero* Faixa } \\
\text { Etária }\end{array}$ & 0,040 & 0,960 & 0,041 & 0,026 & 0,072 & 0,666 \\
\hline
\end{tabular}

Diagnóstico: Encontrado diferenças de médias significativas no construto intenção de continuidade de uso em função da faixa etária

\begin{tabular}{c|c|c|c|c|c}
\hline $\begin{array}{c}\text { Testes univariados - Faixa } \\
\text { Etária }\end{array}$ & $\begin{array}{c}\text { Soma de } \\
\text { quadrados }\end{array}$ & $\boldsymbol{F}$ & Efeito & Sig. & $\begin{array}{c}\text { Poder } \\
\text { observado }\end{array}$ \\
\hline Pretensão de uso & 136,219 & 4,764 & 0,054 & $\mathbf{0 , 0 0 1}$ & 0,952 \\
\hline Intenção de uso & 90,792 & 3,178 & 0,037 & $\mathbf{0 , 0 1 4}$ & 0,822 \\
\hline Regularidade no uso & 157,707 & 4,784 & 0,054 & $\mathbf{0 , 0 0 1}$ & 0,953 \\
\hline
\end{tabular}

A faixa etária é a única variável que apresenta diferenças significativas, com significância de 0,000 e poder observado de 0,979 . A faixa etária também influencia as três variáveis dependentes, demonstrando existir diferenças significativas de avaliação tanto da satisfação como da continuidade de uso. Os testes post-hoc (Tabela 6) identificam em quais estratos de faixa etária as diferenças são significativas.

Tabela 6: Teste post-hoc para Intenção de continuidade de uso versus Faixa etária

\begin{tabular}{c|c|c|c}
\hline Testes post-hoc & Tamhane's T2 & Sig. & Relação de estratos \\
\hline \multirow{2}{*}{ Pretensão de uso } & 1,5731 & 0,002 & 18 a 25 e 36 a 45 \\
& 1,6061 & 0,006 & 18 a 25 e 46 a 55 \\
\hline \multirow{2}{*}{ Intenção de uso } & 1,3486 & 0,016 & 18 a 25 e 36 a 45 \\
& 1,2988 & 0,051 & 18 a 25 e 46 a 55 \\
\hline \multirow{2}{*}{ Regularidade no uso } & 1,5733 & 0,001 & 18 a 25 e 36 a 45 \\
& 1,3004 & 0,027 & 18 a 25 e 46 a 55 \\
\hline
\end{tabular}

Os testes post-hoc verificaram diferenças nos estratos similares aos identificados na satisfação. Diferentemente do construto Satisfação, foi concluído que há diferenças significativas nas três variáveis de intenção de continuidade de uso entre aqueles com idades entre 18 e 25 anos e os com idades de 46 a 55 anos.
Como não foram diagnosticadas diferenças nas médias pela combinação de gênero e faixa etária, os gráficos de interação não são relevantes nesse caso. $\mathrm{O}$ teste Roy Bargman foi utilizado para o construto apenas pela faixa etária (Tabela 7), haja vista que gênero e a interação entre gênero e faixa etária não se mostraram significativas nos testes univariados.

Tabela 7: Teste Stepdown /Roy-Bargman para o construto intenção de continuidade de uso

\begin{tabular}{c|c}
\hline \multicolumn{2}{c}{ Stepdown para Faixa Etária } \\
\hline Variáveis & Sig. dos testes \\
\hline COS1; COS2; COS3 & $\mathbf{0 , 0 0 1} ; 0,928 ; 0,374$ \\
\hline COS2; COS1; COS3 & $\mathbf{0 , 0 0 7} ; 0,163 ; 0,374$ \\
\hline COS3; COS1; COS 2 & $\mathbf{0 , 0 0 1} ; 0,484 ; 0,777$ \\
\hline COS1; COS3; COS 2 & $\mathbf{0 , 0 0 1} ; 0,500 ; 0,777$ \\
\hline COS3; COS2; COS 1 & $\mathbf{0 , 0 0 1} ; 0,910 ; 0,376$ \\
\hline COS2; COS3; COS 1 & $\mathbf{0 , 0 0 7} ; 0,162 ; 0,376$ \\
\hline
\end{tabular}

Os resultados mostram que há significância apenas quando as variáveis são atribuídas individualmente, demonstrando que as três variáveis do construto se bastam. Nesse caso, faria sentido utilizar ANOVA para cada variável dependente. No entanto, sem a utilização da MANOVA não seria possível identificar o modelo de interação nem ao menos ranquear as variáveis pelo poder de diferenciação das médias. As variáveis COS1 e COS3 contribuem para os modelos com mais de uma variável em intensidade similar, enquanto que a COS2 é a que menos contribui para tais modelos. 


\section{Resultados e Discussão}

As variáveis demográficas foram utilizadas como possíveis influenciadoras dos níveis de satisfação e de intenção de continuidade de uso. A grande presença do público jovem na amostra da pesquisa se deve à renovação constante do quadro de pessoal das instituições públicas que serviram de unidades de análise. No Brasil, o concurso público tem atraído os jovens com oferta de bons salários e estabilidade. Essa tendência entra em consonância com as recentes reformas políticas que enfatizam a capacitação do servidor público como fator determinante para a melhoria de desempenho do Estado, através da Política Nacional de Desenvolvimento de Pessoal, instituída pelo Decreto n. 5707 de 23 de Fevereiro de 2006.

Os resultados das variáveis de satisfação apontaram que os funcionários das organizações estudadas estão satisfeitos com os cursos de capacitação à distância. Como consequência, há grande intenção de continuidade de uso dos serviços de e-learning. Na avaliação de relação entre as variáveis dependentes de satisfação e intenção de continuidade de uso com as variáveis do perfil, a faixa etária e a interação gênero versus faixa etária mostrou diferenças entre médias relevantes, revelando opiniões divergentes entre estratos de faixa etária e de gênero. Com base nos resultados, percebe-se que o público mais jovem tende a gerar avaliações mais positivas na avaliação dos cursos avaliados.

Os achados desta pesquisa indicam boa aceitação de cursos a distância oferecidos a funcionários de organizações públicas, além de corroborar outros resultados encontrados na literatura pesquisada (Chiu et al., 2005; Hung \& Cho, 2008; Pires \& Costa, 2008; Chou et al., 2010; Erdogmus \& Esen, 2011; Liao et al., 2011; Cheung \& Lee, 2011; Lin, 2011; Lin \& Chen, 2012; Kim et al., 2012).

Em relação ao gênero, não foram encontradas diferenças significativas de opiniões entre homens e mulheres referentes à sua satisfação com cursos $e$ learning e sua intenção de continuidade em seu uso. Tais resultados foram diferentes dos encontrados por Gomez et al. (2012) e Summak, Baglibel e Samancioglu (2010), que diagnosticaram diferenças de auto avaliação por gênero, mas não de faixa

\section{Considerações Finais}

Esse artigo analisou se existem diferenças nas médias de satisfação e intenção de continuidade de etária. Gomez e colaboradores (2012) concluíram que as mulheres estão mais satisfeitas do que os homens. Porém, os resultados foram similares aos encontrados por Fontes (2006) em um estudo de gênero utilizando como escopo teórico o índice de pré-disposição no uso da tecnologia.

Esses resultados indicam o direcionamento das decisões de gestão, que devem ser estabelecidos reunindo esforços que aumentem a satisfação do público acima de 35 anos. A busca por maiores índices de satisfação do público acima de 35 anos indica a necessidade de ações que preencham lacunas ainda não atendidas por essa parcela de usuários de e-learning. Summak, Baglibel e Samancioglu (2010) destacam que mudanças com foco na satisfação do público menos satisfeito são necessárias para que o curso de capacitação obtenha sucesso entre os funcionários, além de contribuir com o desenvolvimento das TICs. Tais mudanças podem ser implementadas por meio da identificação de necessidades do público mais velho e de que forma a experiência deste público pode ser melhorada.

Gomez et al. (2012) salientam que estudos dessa natureza oferecem informações detalhadas do público mais inclinado a participar ativamente dos cursos de capacitação à distância. A diferença entre os públicos identificados requer uma avaliação observando os diferentes aspectos dos cursos, tais como a experiência de uso no AVA, a facilidade de uso, tempo dedicado aos cursos de capacitação, a integração entre o público mais satisfeito e menos satisfeito, possíveis dificuldades no uso da tecnologia, entre outras características.

Fatores críticos na implementação de serviços de e-learning também devem ser considerados, integrando as TICs em um processo educacional $\mathrm{e}$ como forma de capacitação na gestão pública. Estudos como o de Chiu e colaboradores (2005), Biasutti (2011) e Kim e colaboradores (2012), elucidam que expectativas superestimadas em relação ao curso podem levar a menores níveis de satisfação.

uso de usuários de serviços de e-learning em função do gênero e da faixa etária de, sendo objeto de estudo funcionários de duas organizações públicas no estado do RN, sendo elas a UFRN e o MPRN. O interesse do estudo foi determinar diferentes níveis 
de satisfação e de intenção de continuidade de uso inserido no contexto do e-learning em organizações públicas, e assim, atingiu o objetivo proposto.

A capacitação dos funcionários por meio do $e$ learning gera impactos significativos na sociedade, pois influencia diretamente o serviço prestado ao cidadão, comprovando a necessidade de capacitar os servidores públicos com eficácia (Nascimento, Ramos \& Oliveira, 2011). Os resultados mostram que os funcionários do MPRN e da UFRN quanto mais jovens, maior o nível de satisfação e desejo de continuar realizando os cursos a distância.

Estudos dessa natureza "fornecem aos pesquisadores novas percepções sobre o que deve ser especulado acerca da satisfação no contexto de aplicações baseadas na web" (Cheung \& Lee, 2011, p. 378). A percepção das diferenças de satisfação e de intenção de continuar a usar o serviço de $e$ learning entre características etárias e de gênero do público de e-learning poderá ajudar aos gestores a compreender as necessidades dos funcionários e consequentemente tomar decisões que resultem em melhor desempenho dos funcionários nos cursos e economia de recursos por evitar a realização de cursos ineficazes (Gomez et al. 2012). Além disso, podem ser realizadas mudanças que adequem a oferta dos cursos de $\mathrm{EaD}$ de acordo com as diferenças de faixa etária, sendo esta variável a que apresentou maior diferença nas médias.

Este estudo apresenta algumas limitações. Primeiramente, os resultados não podem ser generalizados, servem apenas de base comparativa, porém, o estudo pode ser replicado em outras unidades de análise (Hair et al. 2009). Sugere-se que o estudo seja testado em outros ambientes organizacionais, incluindo organizações públicas, para fomentar pesquisas acadêmicas e expandir uma base de conhecimento ligada a esse tema.

Lin (2011) e Biasutti (2011) salientam em seus estudos a ausência de fatores culturais das organizações, além de não contemplar fatores externos e possíveis efeitos derivados de condições ambientais ou da natureza de cada organização. A ausência desses aspectos também é evidenciada na pesquisa. Esse fato se deve à dificuldade de tornar o modelo de estudo mais complexo, comprometendo sua viabilidade. Para suprimir essas limitações de viabilização, futuros estudos podem focar em especificidades, tais como: estudos exclusivos de gênero, de idade ou sobre um determinado aspecto particular do serviço de e-learning ou de outro serviço de base tecnológica aplicado a organizações públicas.
Por fim, é sugerido que futuras pesquisas continuem a explorar aspectos ligados a satisfação e a intenção da continuidade de uso em serviços de $e$ learning, como sugerem Cheung e Lee (2011), Chiu e colaboradores (2005), Kim e colaboradores (2012), Lee (2010), Terzis, Moridis e Economides (2013), entre outros. Também é sugerida a condução de modelos comparativos entre funcionários de organizações públicas e de organizações privadas, buscando destacar particularidades e possíveis diferenças no comportamento dos funcionários ao realizar um curso de capacitação à distância.

\section{Referências}

Almeida, M. E. (jul/dez de 2003). Distance learning on the internet: Aproaches and contributions from digital learning environments. Educação $e$ Pesquisa, 29(2), p. 327-340.

Araújo, E. A., Rios, L. C., \& Machado, E. C. (2005). Uma proposta de ensino a distância na justiça eleitoral para melhoria do atendimento ao eleitor. Congresso Internacional de Educação à Distância - ABED.

Barbosa, M. S. (2007). E-learning - Um conceito a ser seguido. (Dissertação de Mestrado em Gestão de Operações). Universidade Lusíada de Vila Nova de Familicão.

Biasutti, M. (2011). The student experience of a collaborative e-learning university module. Computers \& Education, 57, p. 1865-1875.

BRASÍLIA. (2006). Decreto n. 5707 de 23 de Fevereiro de 2006. Institui a Política e as Diretrizes para o Desenvolvimento de Pessoal da administração pública federal. Recuperado de: https://www.planalto.gov.br/ccivil 03/ Ato20042006/2006/Decreto/D5707.htm.

Carvalho, N. (2009). Dimensões da qualidade em um ambiente virtual de aprendizagem. (Tese de Doutorado). Faculdade de Economia, Administração e Contabilidade. Universidade de São Paulo.

Cheung, C. M., \& Lee, M. K. (2011). Antecedents and consequences of user satisfaction with an $e$ learning portal. International Journal of Digital Society, 2(1).

Chiu, C. M., Hsu, M. H., Sun, S. Y., Lin, T. C., \& Sun, P. C. (2005). Usability, quality, value and $e-$ learning continuance decisions. Computers \& Education, 45, p. 399-416. 
Chou, S. W., Min, H. T., Chang, Y. C., \& Lin, C. T. (2010). Understanding continuance intention of knowledge creation using extended expectationconfirmation theory: An empirical study of Taiwan and China online communities. Behaviour \& Information Technology, 29(6), p. 557-570.

Duque, L. C., \& Weeks, J. R. (2010). Towards a model and methodology for assessing student learning outcomes and satisfaction. Quality Assurance in Education, 18(2), p. 84-105.

Enap. (2008). Educação à distância em organizações públicas. Mesa Redonda de Pesquisa-Ação ENAP.

Erdogmus, N., \& Esen, M. (2011). An investigation of the effects of technology readiness on technology acceptance in e-HRM. Procedia Social and Behavioral Sciences, 24, p. 487-495.

Finch, Holmes W. Performance of the RoyBargmann Stepdown procedure as a follow up to a significant MANOVA. (2007). Multiple Linear Regression Viewpoints, 33(1).

Fontes, M. A. (2006). Diferença entre homens e mulheres na propensão em adotar produtos e serviços de tecnologia digital. (Dissertação de Mestrado em Administração). Escola Brasileira de Administração Pública e de Empresas, Fundação Getúlio Vargas.

Fu, Z., Yue, J., Li, D., Zhang, X., Zhang, L., \& Gao, Y. (2007). Evaluation of learner adoption intention of e-learning in China: A methodology based on perived innovative attributes. New Zealand Journal of Agricultural Research, 50, p. 609-615.

Galinkin, C. (2010). Interações de M-learning para usuários com restrições decorrentes da idade. (Dissertação de Mestrado). Pontíficia Universidade Católica de Minas Gerais.

GESPÚBLICA. (2008). Programa Nacional de Gestão Pública e Desburocratização - Prêmio Nacional da Gestão Pública - PQGF; Instruções para Avaliação da Gestão Pública -2008/2009. Brasília, MP, SEGES.

Gil, A. C. (1999). Métodos e técnicas de pesquisa social. São Paulo: Atlas.

Gomez, F. G., Guardiola, J., Rodriguez, O. M., \& Alonso, M. A. (2012). Gender diferences in $e$ learning satisfaction. Computers \& Education, 58 , p. $283-290$.
Hair, J. F., Babin, B., Money, A. H., \& Samouel, P. (2010). Fundamentos de métodos de pesquisa em administração. São Paulo: Arkmed/Bookman.

Hair, J., Anderson, R., Taham, R., \& Black, W. (2009). Análise multivariada de dados (6 ed.). Porto Alegre: Bookman.

Huertas, A. (2007). Teaching and learning logic in a virtual learning environment. Oxford University Press, 15(4).

Hung, H., \& Cho, V. (2008). Continued usage of $e$ learning communication tools: A study from the learners perspective in Hong Kong. International Journal of Training and Development.

Kaplan, E., \& Leiserson, E. (2012). E-learning glossary. Recuperado de: http://www.learningcircuits.org/glossary.html.

Kim, K., Trimi, S., Park, H., \& Rhee, S. (Out. de 2012). The impact of CMS quality on the outcomes of e-learning systems in higher education: An empirical study. Decision Sciences Journal of Innovative Education, 4(4).

Lai, M. L. (2008). Technology readiness, internet self-efficacy and computing experience of professional accounting students. Campus-Wide Information Systems, 25(1).

Langford, J., \& Seaborne, K. (2008). To click or not to click: E-learning for the public sector. Canadian Public Administration, 46(1), p. 50-75.

Lee, M. C. (2010). Explaining and predicting users continuance intention toward e-learning: An extension of the expectation confirmation model. Computers \& Education, 54, p. 506-516.

Liao, C., Chuang, C. L., Yu, P. L., Lai, T., \& Hong, N. L. (2011). Aplying the expectancy disconfirmation and regret theories to online consumer behavior. Cyberpsychology, Behavior and Social Networking, 14(4), p. 241-248.

Lin, K. M. (2011). E-learning continuance intention: Moderating effects of user $e$-learning experience. Computers \& Education, 56, p. 515-526.

Lin, T. C., \& Chen, C. J. (2012). Validating the satisfaction and continuance intention of $e$ learning systems: Combining TAM and IS success models. International Journal of Distance Education Technologies, 10(1), p. 4454.

Magalhães, M. N., \& Lima, A. C. (2002). Noções de probabilidade e estatística. São Paulo: Editora da Universidade de São Paulo. 
Masoumi, D. (2010). Critical factors for effective elearning. Recuperado de $<$ http://asianvu.com/digitallibrary/elearning/Critical factors for effective e -learning by DMasoumi[1].pdf $>$.

Middlehurst, R., \& Woodfield, S. (2006). Quality review in distance learning: Policy and practice in five countries. Tertiary Education and Management, 12, p. 37-58.

Moore, M. G., \& Kearsley, G. (2007). Educação à distância: Uma visão integrada. São Paulo: Thomsom Learning.

Nascimento, T. C., Ramos, A. S., \& Oliveira, P. J. (2011). Prontidão tecnológica e satisfação de alunos na modalidade a distância: $\mathrm{O}$ caso de um programa de capacitação de um governo estadual. REGE: Revista de Gestão, 18(3), p. 489-509.

Nicholson, P. (2007). A history of e-learning: Echoes of the pioneers. In: Manjón, B. F., Elearning: From theory to practice. Dordrecht: Springer, p. 241.

Niper, S. (1989). Third generation distance learning and computer conferencing. In: Mason, R. \& Kaye, A. Mindweave: Comunnication, computers and distance education. Pergamon Press.

Oliver, R. L. (1980). A cognitive model of the antecedents and consequences of satisfaction decisions. Journal of Marketing Research, 17(4), p. 460-469.

Palkovits, S., Lorente, J., Karagiannis, D. (2002). Elearning and e-government: An aproach for process-based training and learning in the public administration. Workshop on E-government: Legal, technical and pedagogical aspects. University of Saragoza.

Pereira, F. A. (2013). A satisfação e a intenção de continuidade de uso em serviços de e-learning: validação empírica de um modelo aplicado em organizações públicas. (Dissertação de Mestrado). Universidade Federal do Rio Grande do Norte.

Pereira, F. A.; Ramos, A. S.; Gouvêa, M. A.; Costa, M. F. (2015). Satisfaction and continuous use intention of e-learning service in brazilian public organizations. Computers in Human Behavior. 46, p. 139-148.

Pinheiro, V. F. (2004). Modelo organizacional de educação à distância para instituições de ensino. (Tese de Doutorado), Instituto de Pesquisas Energéticas e Nucleares. Universidade de São Paulo (USP).
Pinho, J. C., \& Macedo, I. M. (2008). Examining the antecedents and consequences of online satisfaction within the public sector: The case of taxation services. Transforming Government, 2(3), p. 177-193.

Pires, P. J., \& Costa, B. F. (2008). Fatores do índice de prontidão à tecnologia (TRI) como elementos diferenciadores entre usuários e não usuários de internet banking e como antecedentes do modelo de aceitação de tecnologia (TAM). Revista de Administração Contemporânea - RAC, 12(2), p. 429-456.

Saha, P., Nath, A., \& Sangari, E. (2010). Success of government e-service delivery: Does satisfaction matter? Lectures Notes in Computer Science, $1(1)$, p. 204-215.

Sano, H., Abrucio, F. L. (2008). Promessas e Resultados da Nova Gestão Pública no Brasil: o Caso das Organizações Sociais de Saúde em São Paulo. RAE-Revista de Administração de Empresas, 48(3).

Silva, A. S. (2009). Estudo da relação entre domínio tecnológico, interação e aprendizagem "colaborativa" na EAD on-line pelo uso de um modelo de equações estruturais. (Tese de Doutorado). Universidade Federal do Ceará.

Silva, E. L., \& Menezes, E. M. (2001). Metodologia da pesquisa e elaboração de dissertação. Florianópolis: Laboratório de Ensino à Distância da UFSC.

Spreng, R. A., Mackenzie, S. B., \& Olshavsky, R. W. (1996). A re-examination of the determinants of consumer satisfaction. Journal of Marketing, 60 , p. 15-32.

Summak, S., Baglibel, M., \& Samancioglu, M. (2010). Technology readiness of primary school teachers: A case of study in Turkey. Procedia Social and Behavioral Sciences, 2(1), p. 26712675.

Terzis, V., Moridis, C., \& Economides, A. (2013). Continuance acceptance of computer based assessment through the integration of user's expectations and perceptions. Computers \& Education, 62, p. 50-61.

Vavassori, F., Raabe, B., \& Alice, A. L. (2003). Organização de atividades de aprendizagem utilizando ambientes virtuais: Um estudo de caso. In: Silva, M. Educação Online. São Paulo: Loyola.

Vergara, S. C. (2008). Projetos e relatórios de pesquisa em administração. São Paulo: Atlas. 


\title{
Demografic differences in e-learning courses satisfaction: An analysis with public managers
}

\begin{abstract}
The e-learning is an information and communication technology that has been gaining ground in private and public organizational environments. It also constitutes a mode of teaching in constant development. The study aimed to evaluate satisfaction and intention of continuance of use in elearning services, categorized by demographic variables. The survey presents a quantitative approach (survey online), obtaining a sample corresponding to 343 observations. Data analysis involved the use of multivariate analysis of variance (MANOVA). The results indicate significant differences between the variables of satisfaction and intention of continuance of use by age and the combination of gender and age group. The study has practical implications for intensifying the use of e-learning services for online training in public organizations, as well as disseminating a results evaluation tool capable of evaluating employees' behavior regarding the use of technology by demographic groups.
\end{abstract}

Keywords: E-learning, Satisfaction, Public Management, MANOVA.

\section{Diferencias demográficas en la satisfacción de los cursos de e-learning: Un análisis con gestores púbicos}

\begin{abstract}
Resumen
El e-learning es una tecnología de la información y la comunicación que ha ido ganando terreno en entornos de organizaciones privadas y públicas. También constituye un modo de enseñanza en constante desarrollo. El estudio tuvo como objetivo evaluar la satisfacción y la intención de continuar el uso en los servicios de e-learning, categorizados por variables demográficas. La encuesta presenta un enfoque cuantitativo (encuesta en línea), obteniendo una muestra correspondiente a 343 observaciones. El análisis de datos involucró el uso de análisis de varianza multivariante (MANOVA). Los resultados indican diferencias significativas entre las variables de satisfacción y la intención de continuar el uso por edad y la combinación de sexo y grupo de edad. El estudio tiene implicaciones prácticas para intensificar el uso de los servicios de e-learning para la capacitación en línea en organizaciones públicas, asi como la difusión de una herramienta de evaluación de resultados capaz de evaluar el comportamiento de los empleados con respecto al uso de tecnología por parte de grupos demográficos.
\end{abstract}

Palabras Clave: E-learning, Satisfaction, Gestión Pública, MANOVA.

\section{Sobre os Autores}

\section{Fernando Antonio de Melo Pereira}

Doutorando em Administração pela Universidade de São Paulo (USP)

Professor da Faculdade Metropolitana (FAMEC)

Rua Joaquim Eduardo de Farias, 209, Ed. Sunset, Bl. A, Ap. 1301 - Ponta Negra - Natal - RN - Brasil - CEP 59091-130.

E-mail: fernandopcmm@gmail.com 


\section{Anatália Saraiva Martins Ramos}

Doutora em Engenharia de Produção pela Universidade Federal do Rio Grande do Sul (UFRGS)

Professora do Departamento de Ciências Administrativas (DCA), Universidade Federal do Rio Grande do Norte (UFRN)

Av. Sen. Salgado Filho, 3000 - Lagoa Nova - Centro de Ciências Sociais Aplicadas (Anexo dos Professores), piso 3, sala 9 Natal - Brasil - CEP 59078-970.

E-mail: anataliaramos@gmail.com

\section{Maria Aparecida Gouvêia}

Doutora em Administração pela Universidade de São Paulo (USP)

Professora da Faculdade de Economia, Administração e Contabilidade (FEA), Universidade de São Paulo (USP)

Av. Prof. Luciano Gualberto, 908, Bloco FEA1, Sala E110 - Cidade Universitária - São Paulo - SP - Brasil - CEP: 05508-900

E-mail: magouvea@usp.br

\section{Agradecimentos e Outras informações}

Este artigo é fruto de ações conjuntas dos grupos de pesquisa GESTI (Grupo de Pesquisa Gestão de Sistemas e de Tecnologia de Informação) e GEPEA (Grupo de Estudo de Pesquisa em Estatística Aplicada). 